Niniejsza publikacja jest dostępna na licencji Creative Commons. Uznanie autorstwa-Użycie niekomercyjne-Bez utworów zależnych 3.0 Polska. Pewne prawa zastrzeżone na rzecz autora. Zezwala się na wykorzystanie publikacji zgodnie z licencja - pod warunkiem zachowania niniejszej informacji licencyjnej oraz wskazania autora jako wtaściciela praw do tekstu. Treść licencji jest dostęna na stronie: http://creativecommons.org/licenses/by-nc-nd/3.0/pl/

Lingwistyka Stosowana 16: 1/2016, 47-58

\author{
Katarzyna TRYCZYŃSKA
}

Uniwersytet Wrocławski

\title{
Czy ,glazen huizen” to nadal „szklane domy Żeromskiego”? Tłumacz a kulturowe uwarunkowania przekładu
}

\begin{abstract}
:
Do ,glazen huizen” still stand for „szklane domy Żeromskiego”? The translator and culture-bound translation problems

The article outlines the problem of difficulties resulting from cultural differences encountered by the Dutch translators of two Polish novels: Ferdydurke and Poczatek. Culture is present in such texts produced in a certain literary system and socio-cultural context on nearly every level and it often poses serious translation problems. The author focuses on the choices made by Gerard Rasch and Willem A. Maijer, Herman van der Klei and Chris de Ruig in order to draw conclusions concerning the consequences these decisions have and to state whether the couleur locale of the novels has been preserved. The topic in question is thoroughly analysed from the perspective of the target text reader.
\end{abstract}

\section{Wstęp}

Stawiając sobie pytanie o stopień, w jakim couleur locale oryginału znajduje odzwierciedlenie w przekładzie, warto przywołać słowa jednego z najbardziej utytułowanych i cenionych tłumaczy literatury polskiej, którego można bez cienia wątpliwości określić mianem tłumacza kongenialnego. Mowa tu o Karlu Dedeciusie, który jako idealny przekład literacki postrzega taki, który transponuje do języka docelowego artystyczne walory tekstu wyjściowego przy jednoczesnym zachowaniu wierności dla przekazu treści. Przekład taki Dedecius określa mianem Übertragung, w odróżnieniu od przekładu wiernego, acz nie artystycznego, który nazywa Übersetzung (zob. K. Dedecius 1988: 27). Podjęcie próby jak najpełniejszego oddania w przekładzie znaczeń oryginału wydaje się niezbędne i taką konieczność dostrzega wielu przekładoznawców (zob. S. Bassnett 1991: passim, J. Di 2003: 44, A.P. Frank 2004: 813, K. Hejwowski 2004: passim, B. Schulte 2001: 3, O. Wojtasiewicz 1992: 78). Niemniej jednak problem thumaczenia idealnego nie stanowi już obecnie osi rozważań i dlatego też uwaga zostanie tu poświęcona adekwatności i akceptowalności analizowanych przekładów w obrębie kultury docelowej ${ }^{1}$.

\footnotetext{
${ }^{1}$ Przywołane pojęcia będą tu stosowane w rozumieniu zaproponowanym przez przedstawicieli izraelskiej szkoły przekładu (zob. G. Toury 1995: 60, I. Even-Zohar 1990: passim).
} 
W tym kontekście rodzi się pytanie o efekt końcowy działań translacyjnych holenderskich tłumaczy analizowanych powieści, tj. Ferdudyrke i Początku, które stanowią jednocześnie część korpusu badawczego mojej dysertacji (zob. K. Tryczyńska 2014).

Głównym zamierzeniem niniejszego artykułu jest próba odpowiedzi na powyższe pytanie na podstawie analizy wyborów translatorskich w odniesieniu do wybranych elementów kulturowych. Analizie poddano przekłady dokonane przez Willema A. Maijera, Hermana van der Kleia, Chrisa de Ruiga - thumaczy Ferdydurke - oraz Gerarda Rascha ${ }^{2}$, thumacza Poczatku. Ponadto moim celem jest ukazanie, czy i w jakim stopniu udało się przenieść koloryt lokalny świata przedstawionego powieści do świadomości niderlandzkich odbiorców.

\section{Elementy kulturowe}

Przekład utworów literackich, które są z reguły wyjątkowo silnie zakorzenione w danej kulturze, odzwierciedlają jej specyfikę, a przez to odwołują się w szczególny sposób do kodu kulturowego stanowiącego narzędzie komunikacji danej społeczności, stanowi dla thumacza szczególne wyzwanie. Specyfika kulturowa tekstów literackich jest bez wątpienia widoczna w efekcie końcowym procesu translatorskiego pod warunkiem, że zostanie wyeksponowana przez thumacza oraz gdy jej rola w tekście wyjściowym i docelowym zostanie odpowiednio wyrażona (zob. A. Švejcer 2004: 239). W tego typu tekstach kultura obecna jest na wielu płaszczyznach. W przekonaniu holenderskiego przekładoznawcy, Tona Naaijkensa, „kultura znajduje się wszędzie” (zob. T. Naaijkens 2004: 19, tłum.: K.T.) i przejawia się na każdym poziomie dzieła literackiego, co oznacza, że jest obecna zarówno w jego makro- jak i mikrostrukturze (zob. E. Skibińska 1999: 57), a jej nośnikami są elementy kulturowe.

Nie ulega wątpliwości, że przekłady literatury współtworzą obraz danej kultury, a tym samym literatury danego kraju czy też kręgu kulturowego (zob. P. Boulogne 2013: 66-68). Elementy kulturowe pełnią zatem istotną rolę w tekstach wyjściowych i stają się niezwykle ważne w procesie przekładu. Mogą one ponadto wzbogacić, podkreślić walory i uwypuklić wartość estetyczną i literacką przekładu (zob. U. Eco 2001: 45, T. Naaijkens 2002: 14). Interesujące wydaje się tu porównanie, jakie stosuje S. Evenepoel (2004: 126). Flamandzki przekładoznawca postrzega elementy kulturowe jako klucze, które jeśli zostaną starannie wykute przez thumacza, otwierają przed czytelnikami nowe, nieznane wcześniej światy i horyzonty.

W niniejszych rozważaniach za elementy kulturowe uznaje się takie elementy tekstu, które w określonym kontekście i w określony sposób wykazują związek z kulturą danego kraju. Takie ich pojmowanie stanowi odzwierciedlenie definicji zaproponowanej przez Javiera Franco Aixelá, który określa je mianem culture-specific items (CSIs). W jego rozumieniu są to: „elementy występujące w tekście, których funkcja i konotacje w tekście źródłowym wywołują problem przekładowy w trakcie przenoszenia ich do tekstu

\footnotetext{
${ }^{2}$ Gerard Rasch cieszy się w Niderlandach podobną estymą jak Karl Dedecius w Niemczech. Jego liczne przekłady każdorazowo spotykały się z dobrym przyjęciem czytelników, a sam tłumacz był laureatem wielu prestiżowych nagród, jak np. Martinus Nijhoff Prijs, najważniejszej holenderskiej nagrody dla tłumaczy.
} 
docelowego, przy czym problem ten wynika $\mathrm{z}$ braku danego elementu albo $\mathrm{z}$ jego odmiennego statusu intertekstualnego $\mathrm{w}$ systemie kulturowym odbiorcy tekstu docelowego" (zob. J. Aixelá 1996: 58).

Należy przy tym podkreślić, że elementy kulturowe na ogół kojarzone są z najbardziej skrajnymi obszarami danego języka, natomiast wszystkie przypadki, które można usytuować pośrodku tego systemu, nie są rozpatrywane (zob. J. Aixelá 1996: 57). Niejednokrotnie to właśnie one dostarczają niezwykle ciekawych wyników badań. Na pierwszy rzut oka mogą wydawać się zjawiskami obecnymi zarówno w kulturze wyjściowej, jak i docelowej, zatem pozornie nie sprawiającymi większych trudności w przekładzie. Ich skomplikowana i problematyczna natura objawia się jednak w pełni dopiero w momencie, gdy zostaną niejako oderwane od ich pierwotnego kontekstu i przeniesione na grunt kultury docelowej, w której funkcjonują w zgoła odmienny sposób.

Całościowe rozumienie terminu elementy kulturowe proponują także inni badacze, m.in. polski przekładoznawca Krzysztof Hejwowski (zob. K. Hejwowski 2004: 71-124), który dostrzega dwa źródła problemów translatorskich, a mianowicie różnice w systemach językowych i kulturowych. Ojciec polskiej translatoryki, Olgierd Wojtasiewicz, używa natomiast nieco innego określenia wobec takich elementów tekstu literackiego, określa je mianem aluzji erudycyjnych, przy czym erudycja jest $\mathrm{w}$ jego przekonaniu znajomością konkretnych faktów (zob. O. Wojtasiewicz 1992: 77-78). Panasiuk mówi w tym kontekście o lakunach, które definiuje w następujący sposób: „lakuna jest kulturową niezmienną, która ustala stopień różnicy między kulturami. Powstaje ona w momencie kontaktu międzykulturowego i zostaje zinterpretowana przez odbiorcę jako coś, czego nie ma w swojej własnej kulturze" (zob. I. Panasiuk, 2003: 101). Definicje elementów kulturowych znajdujemy także w rozważaniach wielu innych przekładoznawców: Mony Baker (1992), Paula Armina Franka (1992, 2004), Christiane Nord (1997), Brigitte Schultze (2004) czy też Williego Vandeweghe (2005) ${ }^{3}$.

Niewątpliwą zaletą koncepcji Aixeli jest jej dynamiczny charakter, a dokładniej sposób, w jaki badacz postrzega elementy kulturowe. Autor podkreśla wyraźnie, iż należy rozpatrywać je zawsze w kontekście i konkretnym otoczeniu tekstowym. Ponadto elementy te stają się problemem przekładowym dopiero, gdy zostają odłączone od kultury, do której przynależą, gdy thumacz musi je odpowiednio wyrazić w języku docelowym, w którym nie istnieje dla nich odpowiedni ekwiwalent. Innymi słowy chodzi o sytuację, gdy w języku odbiorców przekładu nie istnieje denotacja i konotacja odpowiednia dla pojęć występujących w oryginale, a więc gdy są one nieznane w języku i kulturze docelowej. Trudność w przekładzie może pojawić się jednak również, gdy elementy te funkcjonują w kulturze docelowej w sposób zupełnie odmienny niż w kulturze wyjściowej. Istotny jest zatem fakt, iż ,culture specific items nie istnieją samodzielnie i zawsze muszą być rozpatrywane w odniesieniu do tekstu docelowego" (zob. T. Naaijkens 2004: 19, tłum.: K.T.). Błędne jest więc założenie o istnieniu stałych CSIs w odłączeniu od kultur, do których odnoszą się analizowane teksty, a także w oderwaniu od funkcji tychże elementów w danym tekście (zob. J. Aixelá 1996: 57).

\footnotetext{
${ }^{3}$ Znamienny jest fakt, iż wielu przekładoznawców porusza kwestię kulturowych uwarunkowań przekładu oraz problem przekładu elementów kulturowych, nie definiując tychże elementów (zob. J. House 2004: 494-504).
} 


\title{
2. Rola thumacza
}

\begin{abstract}
Wszyscy jesteśmy fotografami posługującymi się zmienną ogniskową. Dzięki tej właściwości, poruszając pierścieniem obiektywu, możemy obraz każdego obiektu czy sceny powiększyć lub zmniejszyć, wyodrębnić albo pominąć. Za pomocą tego właśnie mechanizmu manipulujemy obrazami świata. Jedne utrwalamy, inne skazujemy na niebyt. Ale ponieważ każdy w każdej chwili i miejscu ciągle tą zmienną porusza i przestawia, każda rzecz wygląda na milion sposobów - różnie - i w związku $\mathrm{z}$ tym na tych milion sposobów jest również widziana i przeżywana (R. Kapuściński 2002: 11).
\end{abstract}

Subiektywizm w postrzeganiu rzeczywistości oraz dynamiczność tego procesu są nieuniknione i pozwalają za każdym razem dostrzec nowe płaszczyzny obserwowanego zjawiska. Podobnie rzecz ma się w przypadku tworzenia i odbioru przekładu. Powyższy cytat może z jednej strony zostać odebrany jako argument broniący tezy o nieprzetłumaczalności, w tym nawet nieprzekładalności absolutnej (zob. T. Bałuk-Ulewiczowa 2000), z drugiej zaś przyznanie tłumaczowi prawa do odbierania świata przedstawionego utworu i wszystkich jego znaczeń w sposób subiektywny implikuje konieczność zanegowania istnienia tegoż zjawiska. Działania przekładowe bardzo często ocierają się o pewną nieprzekładalność, która bez wątpienia stanowi immanentny element procesu tłumaczenia. Jeśli nawet różnice językowe i kulturowe, a tym samym wywołane przez nie rozbieżności w odbiorze rzeczywistości, sprawiają, że przekład nie jest wiernym odwzorowaniem oryginału, może mimo to stanowić dla czytelnika bezcenne źródło wiedzy o „Innym” oswajanym z kolejnymi przekładami (zob. E. Skibińska 1999: 38). Tłumacz pełni w tym procesie szczególnie istotną rolę pośrednika między narodami, językami, kulturami i literaturami. Jako swego rodzaju łącznik międzykulturowy przyczynia się do kreowania obrazu „Innego”, a jednocześnie kształtuje poniekąd tożsamość narodową. Dlatego też wybiera strategie $\mathrm{i}$ techniki tłumaczeniowe niezwykle starannie, mając na uwadze wartości panujące w kulturze docelowej, a zatem bliskie czytelnikowi przekładu oraz zachowanie istotnych elementów tekstu wyjściowego. Świadomy swojej funkcji thumacz dokonuje operacji translacyjnych niejako dwuetapowo. Poddaje on oryginał podwójnej interpretacji, w pierwszej kolejności wykorzystuje swoją kompetencję komunikacyjną w języku i kulturze wyjściowej, a następnie odwołuje się do możliwości językowo-kulturowych potencjalnych czytelników przekładu (zob. G. Lüdi 1987: 60, cyt. za E. Skibińska 2004).

Jako mediator $\mathrm{w}$ dialogu między kulturami tłumacz musi przezwyciężać różnego rodzaju bariery, a także wspomnianą powyżej relatywność w pojmowaniu, powodowaną dorastaniem w określonym środowisku językowym i kulturowym. Teksty literackie oraz teksty o charakterze kulturoznawczym zakorzenione mocno w kulturze danego kraju nasycone są wyrażeniami i znaczeniami typowymi dla konkretnego kręgu kulturowego, a elementy kulturowe, które pojawiają się niemal w każdym takim tekście, sprawiają największą trudność w thumaczeniu i niejednokrotnie uchodzą za nieprzetłumaczalne (zob. W. Koller 1997: 163). W tym kontekście refleksja J. House stanowi pewną przeciwwagę dla powyższego stanowiska. Badaczka konstatuje, iż nie należy kłaść zbyt dużego nacisku na różnice kulturowe. Istniejące rozbieżności tłumacz powinien odpowiednio przeanalizować, a następnie dzięki znajomości języka oraz kultury docelowej właściwie wyrazić w przekładzie (zob. J. House 2004: 500). 
Nie ulega wątpliwości, że kompetencja językowa jest niewystarczająca, by we właściwy sposób przetransponować kontekst kulturowy oryginału na grunt kultury, w której będzie funkcjonował przekład. Niezbędne jest także posiadanie kompetencji interkulturowej oraz komunikacyjnej. Ostatnia z wymienionych kompetencji postrzegana jest jako nadrzędna (zob. A. Małgorzewicz 2014: 3$)^{4}$. Uwzględnienie norm panujących w kulturze docelowej, jak również specyfiki kulturowej oryginału zapewnia skuteczność działań i decyzji translacyjnych. Przekład jest bowiem procesem interlingwalnym i interkulturowym (zob. H. Vermeer 1986: 50), którego celem jest transfer kulturowy (zob. T. Naaijkens 2004: 17). Chcąc zagwarantować transfer thumacz musi kształtować swoje posunięcia translacyjne stosując filtry kulturowe oraz odczytując oryginał w sposób właściwy dla odbiorców przekładu (zob. J. House 2004: 499, M. Piotrowska 2005: 403). Oznacza to więc, iż powinien być szczególnie wrażliwy na panujące w kulturze docelowej przekonania etyczne, moralne czy też religijne oraz być w stanie dokonać projekcji powstającego tłumaczenia na język i kulturę docelową. Zgodnie z powyższym należy więc postawić pytanie, czy rolą tłumacza jest zwrócenie uwagi czytelników przekładu na wszystkie kulturowo nacechowane elementy oryginału, czy jedynie uwrażliwienie na obecność takich elementów i unaocznienie ich w sposób fragmentaryczny. Innym słowy, chodzi o wybór pomiędzy egzotyzacją a adaptacją tekstu, który w swej ekstremalnej formie rodzi zagrożenie polegające na przesadnym nasyceniu tekstu docelowego pojęciami i formami językowymi nieznanymi czytelnikowi, a tym samym utrudnienie właściwego odbioru przekładu. Drugą skrajnością jest z kolei pominięcie elementów specyficznych kulturowo, co w efekcie prowadzić może do całkowitej utraty kolorytu lokalnego tekstu wyjściowego (zob. K. Kwieciński 2001: 13-15).

Tłumacz staje zatem przed arcytrudnym i misternym zadaniem. Dokonując wyborów translatorskich musi bowiem wykazać się wyczuciem, erudycją, a także znajomością realiów i gustu czytelniczego odbiorców przekładu, by w wyniku jego działań powstał tekst, który będzie zapoznawał czytelnika z obcym, otaczając go jednocześnie tym, co znane i rodzime. Proporcje muszą być wyważone, by uzyskać optymalny efekt w postaci tekstu, którego lektura nie przypomina czytelnikowi nieustannie o tym, że ma przed oczyma przekład, a przy tym nie wywołuje zdziwienia poprzez przesadne i nienaturalne udomowienie. Spostrzeżenie to zyskuje na znaczeniu, gdy wspomnimy, że przekład, w którym różnice między tłem kulturowym oryginału i tekstu docelowego zostają pominięte, rzadko bywa czytelny i przystępny. R. Leppihalme twierdzi, iż powstające na skutek takich działań przeszkody - tzw. culture bumps (zob. R. Leppihalme 1997: passim) - wydają się być nie zawsze zauważalne, ale bardzo często stanowią poważną przeszkodę w procesie komunikacji, utrudniając w efekcie odbiór. Kluczowa jest tu ponadto świadomość opiniotwórczego wpływu przekładu na proces kreowania wizerunku kultury, do której należy tekst wyjściowy, w kulturze docelowej. Nie budzi to obecnie żadnych wątpliwości, bowiem ,przekład wywiera ogromny wpływ na budowanie wyobrażeń na temat obcych kultur" (zob. L. Venuti 1998: 67, tłum.: K.T.). Rozpatrując powyższe stwierdzenia z perspektywy socjologii przekładu, można założyć, że tłumacz powinien przewidzieć możliwe luki w doświadczeniach i wiedzy odbiorców przekładu oraz zastosować strategie i techniki translatorskie, by odpowiednio uzupełnić tego rodzaju lakuny.

\footnotetext{
${ }^{4}$ Autorka omawia zasadnicze kompetencje thumacza w kontekście translodydaktyki akademickiej (zob. A. Małgorzewicz 2014: 2-3).
} 


\section{Analiza}

Gerard Rasch oraz Willem A. Maijer, Herman van der Klei i Chris de Ruig, holenderscy thumacze analizowanych powieści, Poczatku A. Szczypiorskiego i Ferdydurke W. Gombrowicza, musieli zmierzyć się z rozmaitymi trudnościami wynikającymi z obecności licznych aluzji obyczajowych, nazw realiów, a także słów nacechowanych emocjonalnie. Na podstawie strategii i technik translatorskich zastosowanych w odniesieniu do elementów kulturowych obecnych $\mathrm{w}$ analizowanych powieściach podjęta zostanie próba zbadania stopnia zachowania kolorytu lokalnego wybranych tekstów. Postaram się także określić ogólny kierunek obrany przez thumaczy w działaniach translacyjnych oraz stopień odtworzenia nacechowania tekstu wyjściowego w przekładzie.

Należy przy tym zaznaczyć, że elementy kulturowe zostały przeanalizowane z perspektywy czytelnika tekstu docelowego i taki też punkt widzenia został obrany podczas dokonywania oceny stopnia udomowienia (domestication) bądź wyobcowania (foreignisation) analizowanych zjawisk. Analiza elementów kulturowych wyekscerpowanych z niderlandzkich przekładów wybranych powieści została przeprowadzona $\mathrm{w}$ oparciu o model zaproponowany przez P. Kwiecińskiego (zob. P. Kwieciński 2001: 157-184) zmodyfikowany w pewnym stopniu na potrzeby niniejszego badania ${ }^{5}$. Analizując trudności, jakie tłumacze napotkali w procesie przekładu, oraz przedstawiając jednocześnie dokonane przez nich wybory translatorskie zastosowano klasyfikację technik thumaczeniowych zaproponowaną w powyższym modelu badawczym.

Analiza przekładu Ferdydurke unaoczniła bezdyskusyjną dominację trzech technik translatorskich. Dwie spośród nich należą do technik egzotyzujących, a trzecia jest przykładem techniki adaptującej tekst przekładu w wyraźny sposób. Łącznie odnoszą się one aż 75\% wszystkich analizowanych CSIs. Poniższe przykłady wydają się być reprezentatywne i pokazują szerokie spectrum zjawisk, do jakich odnoszą się badane elementy kulturowe:

\section{1. borrowing}

Pl. Konrad Wallenrod - Nl. Konrad Wallenrod;

Pl. Endecja - Nl. Endetsia;

Pl. Sokoły - Nl. Sokols;

Pl. king - Nl. 'king'.

2. calque

Pl. Marsz Sokołów - Nl. Sokolmars;

Pl. Dziady - Nl. 'De Bedelaars';

Pl. chłopomania - Nl. boeremanie;

Pl. instytucja "Społem" - Nl. vereniging 'Samenwerking'.

3. covert cultural substitution

Pl. kompot z gruszek - Nl. perenmoes;

Pl. cham - Nl. pummel;

Pl. bigos - Nl. snoekbaars in mayonaise;

Pl. chamskie palce - Nl. plebejersvingers.

${ }^{5}$ Opisując zastosowane techniki tłumaczeniowe posługuję się anglojęzycznymi określeniami zaproponowanymi przez P. Kwiecińskiego ze względu na to, iż często zawierają w sobie kilka technik używanych przez różnych badaczy pod różnymi nazwami, a przez to mają ogólniejszy charakter. Tak dzieje się choćby w przypadku techniki określanej mianem normalisation czy covert cultural substitution (zob. P. Kwieciński 2001). 
Czwartą techniką translatorską stosowaną dość często, bowiem w 15\% przypadków, jest normalisation, a zatem technika gwarantująca wysoki stopień udomowienia, polegająca najczęściej na zastępowaniu wyrażeń tekstu wyjściowego hiponimami lub hiperonimami, bądź neologizmami:

Pl. PKO - Nl. spaarbank;

Pl. kolonia Staszica, kolonia Lubeckiego - Nl. nieuwe wijken;

Pl. szklane domy Żeromskiego - Nl. glazen huizen;

Pl. "Cyrulik Warszawski" - Nl. blad met cabaretliedjes.

W thumaczeniu Poczatku dostrzec można całkowicie inną konstelację. Dominuje w nim jedna technika translatorska wykorzystana w $36 \%$ badanych CSIs. Trzy inne techniki translatorskie stanowią jej wyraźne uzupełnienie i znajdują odzwierciedlenie w $45 \%$ badanych elementów kulturowych. Pozostałe techniki translatorskie stanowią mniejszość i łącznie pojawiają się w 1/5 wszystkich przypadków. Dominująca technika reprezentuje pośrednie techniki translatorskie opatrzone z reguły dość obszernym wyjaśnieniem $\mathrm{w}$ tekście bądź $\mathrm{w}$ przypisie dolnym.

Poniższe przykłady dają pewien obraz specyfiki analizowanych elementów kulturowych w przypadku najczęściej stosowanej techniki translatorskiej:

1. borrowing + gloss

Pl. Orzeszkowa - N1. Orzeszkowa ${ }^{6}$;

Pl. na Szucha - Nl. in de Szuchstraat;

Pl. Pawiak - Nl. Pawiakgevangenis;

Pl. Marszałek - Nl. 'de Marschalk'?

Trzy techniki, o których mowa powyżej, należą do różnych kategorii i reprezentują odpowiednio techniki asymilujące, pośrednie oraz egzotyzujące:

2. normalisation

Pl. podsędek - Nl. rechter;

Pl. Bezpieka - Nl. Veiligheidsdienst;

$\mathrm{Pl}$. rogatywka - Nl. pet;

$\mathrm{Pl}$. oenerowcy $-\mathrm{Nl}$. nationaal-radicalen.

3. calque + gloss

Pl. sarmacka polskość - Nl. Sarmatische ${ }^{8}$ Pool;

Pl. kampania wrześniowa - Nl. septembercampagne van 1939;

Pl. sanacja - Nl. sanatie

Pl. szklane domy $-\mathrm{Nl}$. glazen huizen ${ }^{10}$.

${ }^{6}$ Orzeszkowa: Eliza Orzeszkowa (1841-1910), eerste grote Poolse schrijfster.

7 de Maarschalk: Józef Pilsudski (1867-1935), onafhakelijkheidsstijder, commandant van de Poolse legioenen die in 1914 met Oostenrijk tegen de Russen vochten; was later, na een staatsgreep in 1926, de feitelijke leider van Polen.

${ }^{8}$ Sarmatisch: in de Poolse geschiedenis synoniem voor 'echt' Pools: nationalistisch, provinciaal, conservatief.

9 de sanatie: het kolonelsbewind dat Polen na Pilsudski's dood weer gezond wilde maken (saneren).

${ }^{10}$ glazen huizen: uit de roman 'Voorlente' (1924) van Stefan Zeromski (1864-1925), symbool van de hoop op betere tijden. 


\section{4. borrowing}

Pl. rapaport bielski - N1. Bielitzer Rapaport;

Pl. kacet - Nl. KZ;

Pl. Nowy Kurier Warszawski - Nl. Nowy Kurier Warszawski.

Powyższe przykłady zostały zaprezentowane bez kontekstu, ponieważ ze względów praktycznych nie jest możliwe omówienie każdego nich w oparciu o zastosowany model analityczny z uwzględnieniem poszczególnych etapów analizy, a więc w szerszym kontekście, w jakim się pojawiają. Służą one przede wszystkim pokazaniu bogatego spektrum zjawisk, jakie konstytuują elementy kulturowe, oraz ich relatywnego charakteru.

Na podstawie powyższej analizy można bez wątpienia stwierdzić, iż w obu przekładach zauważalne jest stosunkowo umiarkowane podejście, jednak wybór technik tłumaczeniowych sugeruje dość wyraźne dążenie do egzotyzacji tekstu. Elementy typowe dla polskiej kultury zostały bowiem zachowane, co umożliwiły takie techniki translatorskie, jak zapożyczenie czy kalka. Są one więc widoczne dla czytelników przekładu, a ponadto w wielu przypadkach zostały opatrzone dodatkowymi komentarzami bądź odwołaniami. Powyższe wnioski należy jednak uznać za niepełne, gdyż ocena zastosowanych rozwiązań translatorskich ulega jednak pewnej zmianie, gdy wybrane elementy kulturowe przeanalizujemy w kontekście. Zauważymy wówczas, że technika egzotyzująca może przynieść efekt, który można w zasadzie założyć w oparciu o jej charakter, mianowicie przekłada się na poziomie makrostrukturalnym na wyobcowanie. Tak też się dzieje w pierwszym przytoczonym przykładzie z tłumaczenia Ferdydurke. Dla czytelników przekładu nie jest to oczywiste, że wspomniana nazwa własna, Konrad Wallenrod, jest jednocześnie tytułem poematu literackiego, który odegrał znaczącą rolę dla polskiej historii literatury. Nierzadko jednak kontekst znacząco zmienia sposób odbierania danego elementu kulturowego przez czytelników przekładu czego dowodzą chtopomania oraz rapaport bielski. W obu przypadkach w wyniku zastosowania egzotyzującej techniki translatorskiej (borrowing) elementy te są dostrzegane przez czytelników, których thumacz prowadzi tym samym w stronę oryginału, a mimo to za sprawą kontekstu są one całkowicie zrozumiałe i na poziomie makrostrukturalnym mamy do czynienia $\mathrm{z}$ udomowieniem.

Podobne spostrzeżenie dotyczy technik asymilujących, w przypadku których możemy mówić o uzyskaniu efektu pełnego udomowienia, co jest najbardziej oczywistym i najczęstszym wynikiem takich zabiegów translatorskich. Dowód stanowią praktycznie wszystkie przytoczone przykłady zastosowania covert cultural substitution oraz normalisation. Niemniej jednak zastosowanie takich technik może przynieść zgoła odmienny rezultat i doprowadzić nawet do wyobcowania. Pewne zdziwienie czytelników przekładu Początku może wywołać zastąpienie bigosu dość nietypową potrawą - snoekbaars in mayonaise, w tłumaczeniu dosłownym to sandacz w majonezie. Nie jest ona bowiem ani popularna w kulturze niderlandzkiej, ani nie wpisuje się w kontekst, $\mathrm{w}$ jakim się pojawia.

Techniki pośrednie stosowane chętnie przez tłumacza Początku (łącznie aż w ponad połowie przypadków) stają się dzięki kontekstowi zazwyczaj w pełni zrozumiałe, a przy tym udaje się zachować koloryt lokalny oryginału. I tak oto czytelnicy dostrzegają element obcy w postaci nieznanych im, acz zrozumiałych nazw własnych, takich jak: in de Szuchstraat, Pawiakgevangenis czy sanatie. Tłumaczenie to oscyluje więc na poziomie makrostrukturalnym w kierunku strategii udomowienia. 
Na pewną uwagę zasługuje element kulturowy obecny w obu powieściach, mowa tu o odniesieniu do szklanych domów z Przedwiośnia Stefana Żeromskiego. Zostaje on przethumaczony przez trio translatorskie: Maijer, van der Klei oraz Ruig przy pomocy udomawiającej techniki (normalisation), natomiast Rasch stosuje kalkę oraz przypis, a zatem technikę pośrednią. W pierwszym przypadku element ten okazuje się być niewidoczny dla niderlandzkojęzycznych odbiorców, a użyty hiperonim wywołuje pewną konsternację, gdyż fragment, w którym występuje, częściowo traci spójność. W drugim przypadku dostrzegają oni pewną obcość, jednak zrozumiały jest dla nich zarówno sam element kulturowy, jak i skojarzenia, jakie może wywoływać wśród czytelników oryginału.

Chcąc zatem określić ogólny kierunek, jaki obrali tłumacze, a tym samym podjąć próbę zdefiniowania stopnia odtworzenia w tekście niderlandzkim elementów podkreślających jego obcokulturowe pochodzenie, dochodzimy do wniosku, iż trzech thumaczy Ferdydurke zastosowało wyobcowanie z pewnymi elementami strategii udomowienia, wprowadzając tym samym czytelnika do świata przedstawionego oryginału w sposób przystępny i niezakłócający odbioru. Natomiast przekład Gerarda Rascha można określić mianem poszukiwania złotego środka pomiędzy wyobcowaniem a udomowieniem z zauważalnym dążeniem do zbliżenia tekstu przekładu do kultury wyjściowej poprzez stosowanie technik pośrednich. Techniki te pozwoliły na zachowanie „obcego” oraz wyjaśnienie go tam, gdzie to niezbędne przy pomocy odwołań i zwięzłych komentarzy.

\section{Wnioski}

Przytoczone przykłady elementów kulturowych z wybranych tekstów dowodzą, że elementy kulturowe należy rozpatrywać w kontekście, a efekt końcowy, jaki wywołują, może być niejednokrotnie odmienny i zależy od kontekstu historycznego, kulturowego oraz bezpośredniego otoczenia tekstowego. Szeroko pojęta sytuacja socjokulturowa i ekonomiczna, zmiany geopolityczne w obrębie danej kultury lub ich brak determinują pozycję języka, a jednocześnie także pozycję kultury. Niemały wpływ mają na nią również wydarzenia historyczne. Czynniki te często leżą u podstaw decyzji o wyborze konkretnej techniki i strategii thumaczeniowej, która zostaje dopasowana do aktualnego stanu rzeczy i wiedzy o kulturze źródłowej z uwzględnieniem norm kultury docelowej. Zauważalna tendencja wyboru technik egzotyzujących i pośrednich, która w dużej mierze przekłada się na poziomie makrostrukturalnym na umiarkowane wyobcowanie, dowodzi założeń M. Tymoczko (1999) dotyczących języków peryferyjnych, w których przekład odgrywa istotną rolę, tłumacze cieszą się poważaniem i mają wysoki status oraz często stosowane są egzotyzujące techniki tłumaczeniowe.

Wracając do konkretnych przykładów, szczególnie ciekawe są przypadki, gdy użycie egzotyzujących technik translatorskich nie przesądza o ostatecznym efekcie, którym może być niemal całkowite udomowienie - przeciwieństwo wyobcowania, które w takich przypadkach mogłoby wydawać się wręcz oczywiste. Sytuacja wygląda podobnie w momencie, gdy elementy kulturowe zostają przetłumaczone przy użyciu asymilujących technik translatorskich, które w kontekście mogą okazać się absolutnie niezrozumiałe, a co więcej wprowadzać czytelnika w błąd, choć zaznaczyć należy, że taka sytuacja pojawia się nad wyraz rzadko. Nie w każdym przypadku należy jednak uznać je za 
uciążliwe. Jeśli nie utrudniają one lektury, mogą okazać się dla czytelników intrygujące. $\mathrm{Z}$ analizy wynika ponadto, że egzotyzujące techniki translatorskie przynoszą częstokroć taki sam efekt na poziomie makrostrukturalnym prowadząc nawet do wyobcowania ( $f o-$ reignisation) i odwrotnie - asymilujące techniki translatorskie skutkują udomowieniem (domestication).

Reasumując, chciałabym raz jeszcze podkreślić, że w obu przekładach zauważamy konsekwentne stosowanie określonych technik translatorskich, będących wynikiem starannego i świadomego wyboru. Tłumacze zbliżali się w swoich tłumaczeniach nieznacznie w stronę wyobcowania. Ich działania były jednak ostrożne i nie doprowadziły do przesycenia przekładów elementami kulturowymi, które są obce i niezrozumiałe dla czytelników. Zarówno Rasch, jak i Maijer, van der Klei oraz Ruig decydują się na rozwiązanie pośrednie, w moim przekonaniu najbardziej optymalne. Ich przemyślane wybory translatorskie przyczyniają się do powstania przekładów, w których kultura tekstu wyjściowego jest wyeksponowana, tam gdzie to możliwe, a objaśniona tam, gdzie to konieczne.

\section{Bibliografia}

Aixelá, J. F. (1996), Culture-specific Items in Translation, (w:) R. Alvarez/ M.C.A. Vidal (red.), Translation, Power, Subversion. Clevedon-Philadelphia-Adelaide, 52-78.

Baker, M. (1992), In other words. A coursebook on translation. London-New York.

Bałuk-Ulewiczowa, T. (2000), Beyond cognizance: Fields of absolute untranslatability, (w:) W. Kubiński/ O. Kubińska (red.), Przekładając nieprzekładalne. Materiały z I Międzynarodowej Konferencji Translatorycznej. Gdańsk, 173-182.

Bassnett, S. (1991), Translation Studies. London-New York.

Boulogne, P. (2013), Nietes-welles. Waarom vertaalwetenschap wel cruciaal is voor de Receptiewetenschap, (w:) Filter 20 (1), 66-72.

Dedecius, K. (1974/1988), Notatnik thumacza. Warszawa.

Di, J. (2003), Literary translation. Quest for Artistic Integrity. Manchester-Northampton MA.

Eco, U. (2001), Experiences in Translation, thum. A. McEwen. Toronto-Buffalo-London.

Even-Zohar, I. (1978/1990), The Position of Translated Literature within the Literary Polysystem, (w:) Polysystem Studies, Poetics Today 11 (1), 45-51.

Evenepoel, S. (2004), Bij wijze van slot. Zoeken naar sleutels voor Notebooms Hotel, (w:) S. Evenepoel/ G. Rooryck/ H. Verstraete (red.), Taal en cultuur in vertaling. De wereld van Cees Noteboom. Antwerpen-Apeldoorn, 123-127.

Frank, A. P. (1992), Zu einer 'konkreter Theorie' des übersetzerischer Umgangs mit Fremdheitspotential: Waste Land-Übersetzungen französisch und deutsch, (w:) F. Lönker (red.), Die literarische Übersetzung als Medium der Fremderfahrung. Göttingen, 63-68.

Frank, A. P. (2004), Translation research from a literary and cultural perspective: $O b$ jectives, concepts, scope, (w:) H. Kittel/ A.P. Frank/ N. Greiner/ T. Hermans/ 
W. Koller/ J. Lambert/ F. Paul (red.), Übersetzung Translation Traduction. Ein internationales Handbuch zur Übersetzungsforschung. An international Encyclopedia of Translation. Studies Encyclopédie internationale de la recherche sur la traduction. Berlin-New York, 790-851.

Hejwowski, K. (2004), Kognitywno-komunikacyjna teoria przektadu. Warszawa.

House, J. (2004), Culture-specific items in translation, (w:) H. Kittel/ A.P. Frank/ N. Greiner/ T. Hermans/ W. Koller/ J. Lambert/ F. Paul (red.), Übersetzung Translation Traduction. Ein internationales Handbuch zur Übersetzungsforschung. An international Encyclopedia of Translation. Studies Encyclopédie internationale de la recherche sur la traduction. Berlin-New York, 494-504.

Kapuściński, R. (2002), Lapidarium $V$. Warszawa.

Kwieciński, K. (2001), Disturbing strangeness. Torun.

Koller, W. (1979, 1997), Einführung in die Übersetzungswissenschaft. Wiesbaden.

Leppihalme, R. (1997), Culture bumps. An empirical Approach to the Translation of Allusions. Clevedon-Philadelphia-Toronto-Sydney-Johannesburg.

Lüdi, G. (1987), Aspects énonciatifs de la traduction, (w:) Cahiers du Département des Langues et des Scienes du Langage, 5 (La Traduction).

Małgorzewicz, A. (2014), Językowe i niejęzykowe kompetencje thumacza. Próba zdefiniowania celów translodydaktyki akademickiej, (w:) Lingwistyka Stosowana 11, 1-10.

Naaijkens, T. (2002), De slag om Shelley en andere essays over vertalen. Nijmegen.

Naaijkens, T. (2004), Een wereld van verschil. Over taal en cultuur in vertaling, (w:) S. Evenepoel/ G. Rooryck/ H. Verstraete (red.), Taal en cultuur in vertaling. De wereld van Cees Noteboom. Antwerpen-Apeldoorn, 13-23.

Nord, Ch. (1997), Translation as a Purposeful Activity. Functionalist Approaches Explained. Manchester.

Panasiuk, I. (2003), Miejsce modelu lakun w obrębie teorii tlumaczenia kultur, (w:) K. Hejwowski (red.), Teoria i dydaktyka przekładu. Olecko, 99-112.

Piotrowska, M. (2005), Strategia kompensacji w thumaczeniu kultury, (w:) Język Trzeciego Tysiąclecia III, vol. 2. Konteksty przekładowe. Język a komunikacja 8., 397-404.

Schulte, R. (2001), The Geography of Translation and Interpretation. Traveling Between Languages. Lewiston-Queenston-Lampeter.

Schultze, B. (2004), Kulturelle Schlüsselbegriffe und Kulturwörter in Übersetzungen fiktionaler und weiterer Textsorten, (w:) H. Kittel/ A.P. Frank/ N. Greiner/ T. Hermans/ W. Koller/ J. Lambert/ F. Paul (red.), Übersetzung Translation Traduction. Ein internationales Handbuch zur Übersetzungsforschung. An international Encyclopedia of Translation. Studies Encyclopédie internationale de la recherche sur la traduction. Berlin-New York, 926-936.

Skibińska, E. (1999), Przektad a kultura. Elementy kulturowe we francuskich przekładach „Pana Tadeusza”. Wrocław.

Skibińska, E. (2004), W szkole interkulturowości: problematyka różnic między kulturami $w$ dydaktyce przekładu, (w:) Między oryginałem a przekładem IX, 79-90.

Švejcer, A. D. (2004), Possibilities and limitations of linguistic approaches to Translation, (w:) H. Kittel/ A.P. Frank/ N. Greiner/ T. Hermans/ W. Koller/ J. Lambert/ F. Paul (red.), Übersetzung Translation Traduction. Ein internationales Handbuch zur Übersetzungsforschung. An international Encyclopedia of Translation. 
Studies Encyclopédie internationale de la recherche sur la traduction. Berlin-New York, 236-242.

Toury, G. (1995), Descriptive Translation Studies and Beyond. AmsterdamPhiladelphia.

Tryczyńska, K. (2014), Vertaaltendensen in de Nederlandse vertalingen van Poolse hedendaagse romans. Een vergelijkende studie van cultuurgebonden elementen (niepublikowana rozprawa doktorska). Uniwersytet Wrocławski, Wrocław.

Tymoczko, M. (1999), Post-colonial writing and literary translation, (w:) S. Bassnett/ H. Trivedi (red.), Post-colonial Translation. London-New York, 19-41.

Vandeweghe, W. (2005), Duo teksten. Inleiding tot vertaling en vertaalstudie. Gent.

Venuti, L. (1998), The Scandals of Translation: Towards an Ethics of Difference. London. Vermeer, H. (1986), Übersetzen als kultureller Transfer, (w:) M. Snell-Hornby, (red.), Übersetzungswissenschaft - eine Neuorientierung. Zur Integrierung von Theorie und Praxis. Tübingen-Basel, 30-53.

Wojtasiewicz, O. (1957, 1992), Wstęp do teorii ttumaczenia, Warszawa.

\section{Teksty źródłowe}

Gombrowicz, W. (2009 [1938]), Ferdydurke. Kraków.

Gombrowicz, W. (1967), Ferdydurke, thum.: W.A. Maijer/ H. van der Klei/ C. de Ruig. Amsterdam.

Szczypiorski, A. (1991 [1986]), Początek. Poznań.

Szczypiorski, A. (1988), De mooie mevrouw Seidenman, tłum.: G. Rasch. Amsterdam. 